\title{
Throwing Caution to the Wind: National Weather Service Wind Products as Perceived by a Weather-Salient Sample
}

\author{
CASTLE A. WILLIAMS \\ University of Georgia, Athens, Georgia \\ PAUL W. MILLER \\ University of Georgia, Athens, Georgia \\ ALAN W. BLACK \\ Louisiana State University, Baton Rouge, Louisiana \\ JOHN A. KNOX \\ University of Georgia, Athens, Georgia
}

(Manuscript received 11 July 2016; review completed 22 February 2017)

\begin{abstract}
Weather products generated by the National Weather Service (NWS) are crucial for communicating information about weather events. However, it is unclear if the public understands those that exclusively involve wind terminology or the risk posed by nonconvective wind events. To further investigate these questions, we surveyed 373 members of the public from Georgia and Virginia who regularly obtain weather information from two weather blogs in each of the states. Participants completed an online survey designed to evaluate their familiarity with NWS wind products (high wind warning and wind advisory), perceived wind speed thresholds associated with these products, willingness to change plans based on these products, and finally, "weather salience"-the importance participants place on weather information.

It was found that our participants scored higher on the weather salience measure compared to previous studies that examined the general public. In both states, these weather-attentive individuals defined high wind warnings $(\mathbf{5 7 . 5 \%})$ and wind advisories $(31.8 \%)$ in terms of impacts to their daily lives. Respondents also reported that they would be more likely to alter their plans for a high wind watch compared to a wind advisory, providing evidence of a spectrum of understanding about the NWS wind products. Although various NWS initiatives are currently experimenting with the watch/warning/advisory system and impact-based messaging, this study identifies the need to continue and expand this line of research to include all weather hazards (those convective and nonconvective in nature).
\end{abstract}

\section{Introduction}

The National Weather Service (NWS) issues various weather products (watches, warnings, and advisories) that are used to communicate weather information to the general public. Although the NWS disseminates specific products for nonconvective high wind events, in addition to the more prevalent convective weather products, it is unclear if the general public understands wind terminology or the risk associated with nonconvective wind events. From a historical perspective, NWS wind products are fairly new to the world of weather communication. Prior to the 1990s, the NWS presented any wind hazard as a Special Weather Statement to the general public (Friday 1994; personal communication, Steve Nelson, Science and Operations Officer, NWS Peachtree City, GA, 7 May 2015). However, as part of the NWS modernization effort in the early 1990s, the NWS significantly restructured the format (personal communication, Steve Nelson, 7 May 2015) and variety (NWS 1992) of weather products 
that it issued. This effort expanded the set of watches, warnings, and advisories, as well as designated several products that communicate the threat of nonconvective winds. Much of the language in these new alerts was borrowed from previous weather products and the existing watch/warning/advisory system.

The NWS communicates the risk of nonconvective wind hazards through three distinct wind products: the high wind watch, wind advisory (WA), and high wind warning [HWW; (NWS 2015a; NWS 2015b)]. Each product is issued if winds are forecast to meet or exceed a specific threshold and usually involves a temporal component indicating winds are currently occurring or will occur soon ( $<24$ hours; Table 1). However, the suite of nonconvective wind alerts are among a select group of NWS products [excessive heat (NWS 2015b), winter weather (NWS 2016), etc.] designed with varying issuance criteria to account for geographic and climatological factors unique to each Weather Forecast Office's (WFO) county warning area (NWS 2015b). Like other weather warning products, these wind products share a hierarchical structure. When a potential strong nonconvective wind event is forecast for an area, a high wind watch may be issued followed by a possible upgrade to either a WA or HWW depending on local WFO wind speed criteria (NWS 2015a; NWS 2015b).

Previous studies have acknowledged that nonconvective wind events harm as many individuals as winds associated with severe thunderstorms or hurricanes (Mortimer and Kane 2004; Lacke et al. 2007; Ashley and Black 2008; Schmidlin 2009; Knox et al. 2011a). Therefore, the need exists to further examine the public's perception of current wind-specific products and their willingness to react to these alerts. When evaluating a threat, an individual's risk perception and willingness to take protective action often begins by evaluating environmental and social cues (Mileti and Sorensen 1990; Lindell and Perry 2012). Because nonconvective wind events often lack environmental cues present during convective events (e.g., ominous clouds, thunder, etc.), it is unclear whether the public is threatened by and can effectively react to and/or prepare for these events (Knox et al. 2011b). Further, convective events are often associated with multiple hazards beyond the wind (e.g., rain, lightning, hail, etc.) that may prompt protective action. In contrast, nonconvective wind conditions in the absence of these other hazards may be less likely to elicit action. Finally, because wind is an intensity-based hazard and is regularly experienced at low intensities (e.g., a slight breeze), it alone may not be perceived as a high-threat event.

Without environmental cues or multiple hazards to warn of the impending threat, wind hazard messaging must communicate the risks associated with nonconvective wind events. The NWS has updated their Internet-based wind hazard resources; however, the materials lack a clear distinction between convective and nonconvective wind hazards (NWS 2015c). As outlined above, wind hazard messaging should strive to 1) differentiate these hazards by highlighting the warning signs associated with nonconvective wind threats and 2) acknowledge the dangers of wind as a sole threat to encourage individuals to reassess their perceived risk and take action during nonconvective wind events. Therefore, this study will examine a weather-attentive public to better understand their knowledge and familiarity with wind hazard messaging in the United States.

The following section describes the creation of the survey, which was given to residents in select counties in Georgia and Virginia because of their differing frequency of wind products. This result was based on a wind product issuance climatology from Miller et al. (2016a) that revealed a higher frequency of wind product issuance in the state of Virginia compared to Georgia (Fig. 1). These areas also were identified from wind hazard literature stating that both Georgia and Virginia are among the states with the highest death rates from wind-related tree failures and nonconvective wind events (Ashley and Black 2008; Schmidlin 2009). These survey data reveal the participants' familiarity with NWS wind products, their definitions of these products, their thoughts on altering plans because of the issuance of these products, and their opinions on the current language used in wind-specific weather products.

\section{Methods}

\section{a. Procedure}

To specifically focus on surveying individuals who frequently seek weather information, we partnered with two local weather blogs (AthensGaWeather and Roanoke Times: Weather Journal). Weather blog users were chosen specifically in hopes of obtaining a sample of people who would be more interested in or informed about weather terminology and products. It was hypothesized that the behavior associated with visiting a weather blog would act as a proxy 
Table 1. Formal definitions of the NWS wind products from the NWS Glossary (NWS 2015a). Click image for an external version; this applies to all figures hereafter.

\begin{tabular}{|c|c|}
\hline $\begin{array}{l}\text { NWS } \\
\text { Wind } \\
\text { Product }\end{array}$ & Definition \\
\hline $\begin{array}{c}\text { High Wind } \\
\text { Warning }\end{array}$ & $\begin{array}{l}\text { "This product is issued by the National Weather Service when high wind } \\
\text { speeds may pose a hazard or is life threatening. The criteria for this warning } \\
\text { varies from state to state. In Michigan, the criteria is sustained non- } \\
\text { convective (not related to thunderstorms) winds greater than or equal to } 40 \\
\text { mph lasting for one hour or longer, or winds greater than or equal to } 58 \mathrm{mph} \\
\text { for any duration." }\end{array}$ \\
\hline $\begin{array}{c}\text { Wind } \\
\text { Advisory }\end{array}$ & $\begin{array}{l}\text { "Sustained winds } 25 \text { to } 39 \mathrm{mph} \text { and/or gusts to } 57 \mathrm{mph} \text {. Issuance is normally } \\
\text { site specific. However, winds of this magnitude occurring over an area that } \\
\text { frequently experiences such winds" }\end{array}$ \\
\hline $\begin{array}{l}\text { High Wind } \\
\text { Watch }\end{array}$ & $\begin{array}{l}\text { "This product is issued by the National Weather Service when there is the } \\
\text { potential of high wind speeds developing that may pose a hazard or is life } \\
\text { threatening. The criteria for this watch varies from state to state. In } \\
\text { Michigan, the criteria is the potential for sustained non-convective (not } \\
\text { related to thunderstorms) winds greater than or equal to } 40 \text { mph and/or gusts } \\
\text { greater than or equal to } 58 \mathrm{mph} . "\end{array}$ \\
\hline
\end{tabular}

for "weather salience," a term defined by Stewart (2009) as "the degree to which individuals attribute psychological value or importance to the weather and the extent to which they are attuned to their atmospheric environments." Therefore, these individuals were likely to be more familiar with and understand the differences between NWS wind products compared to a random sample of individuals from the general population. The two weather blogs were identified in each targeted location (Georgia and Virginia) owing to their varying frequency of wind events (Figs. 2 and 3). The blogs were contacted and both agreed to advertise the study on their website and social media platforms to their respective coverage areas throughout the study period (Fig. 4). After receiving approval from the Institutional Review Board, the link to the survey was opened and emailed to the weather blogs on 3 April 2015. This link sent the participant to a survey that was administered through the Qualtrics online platform.

The opening page gave a brief description of the research project, asked for signed consent, and notified participants that they must live in 1) Georgia or Virginia and 2) in a county within the blog's coverage area to be considered eligible. If the participant did not wish to complete the survey or did not reside in the selected areas, they were still eligible for the incentive (a drawing for one of three NOAA weather radios) and were immediately redirected to a separate page where they could provide contact information. The respondents who agreed to participate were then informed to begin the survey. Although it is a best practice to address demographic questions at the end of a survey to increase participant engagement and to eliminate any demographic biases, our survey began with these questions to ensure they were completed by each participant. This decision was based on previous survey research in the atmospheric sciences (Stewart et al. 2016) and additional research examining optimal response rates for demographic information (Landers 2011; Teclaw et al. 2012). Upon finishing the survey, 

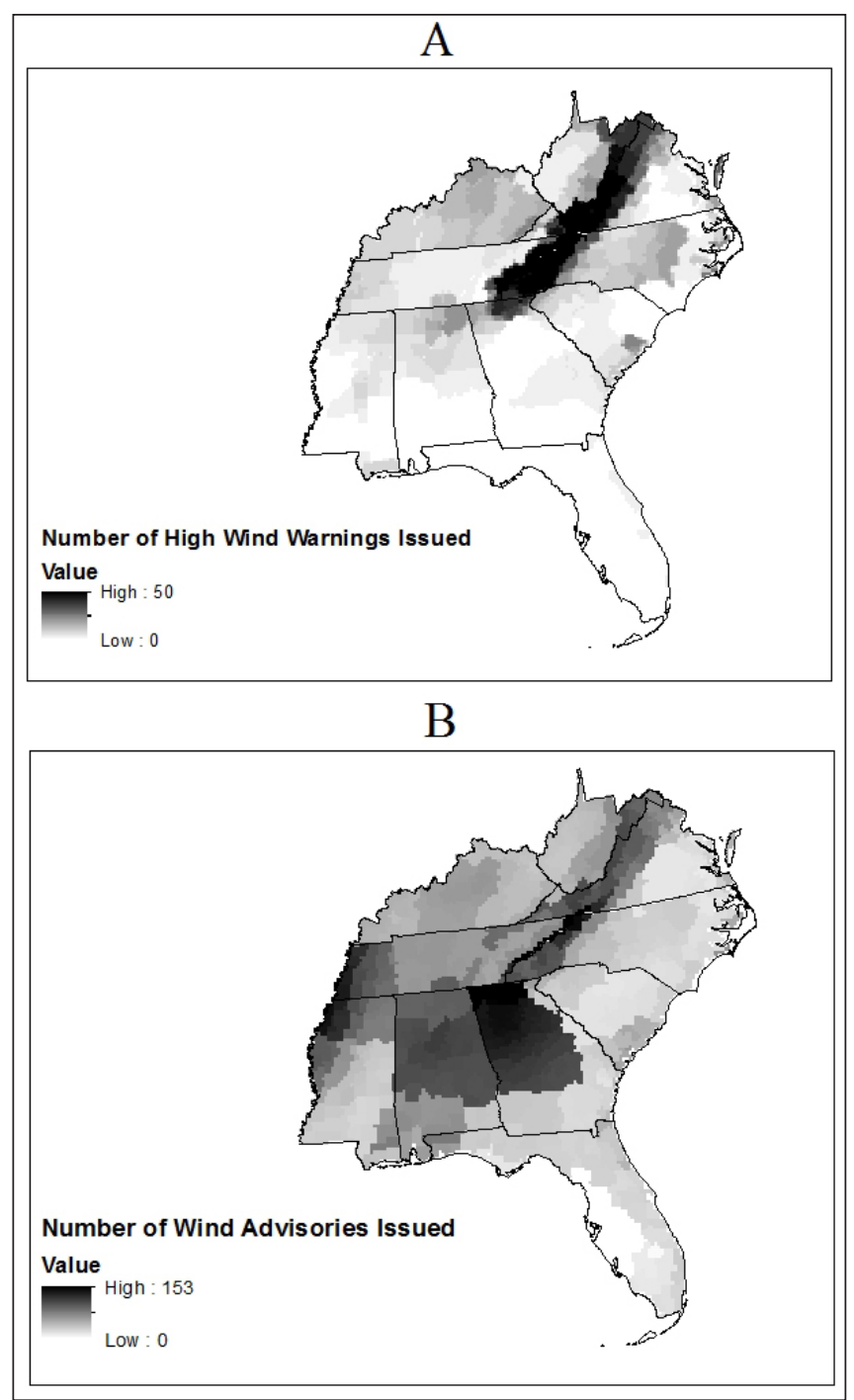

Figure 1. An archive of NWS wind advisories (WAs) and high wind warnings (HWWs) were obtained from the Iowa Mesonet data portal (Iowa Environmental Mesonet 2015) to depict the number of A) WAs and B) HWWs warnings issued by the NWS between 2006 and 2013 for the southeastern United States (Miller et al. 2016a).

responses were recorded, and participants were asked if they would like to provide contact information for the incentive. Two weeks prior to the close of the survey, all the survey respondents were emailed and asked to share the survey with other interested individuals; however, they were specifically told that this would not affect their chances of winning a NOAA weather radio. We closed the survey on 1 June 2015, at which point we had received 337 responses from the local weather blogs and 36 responses from the snowball sampling technique, for a total of 373 complete responses. Although metadata

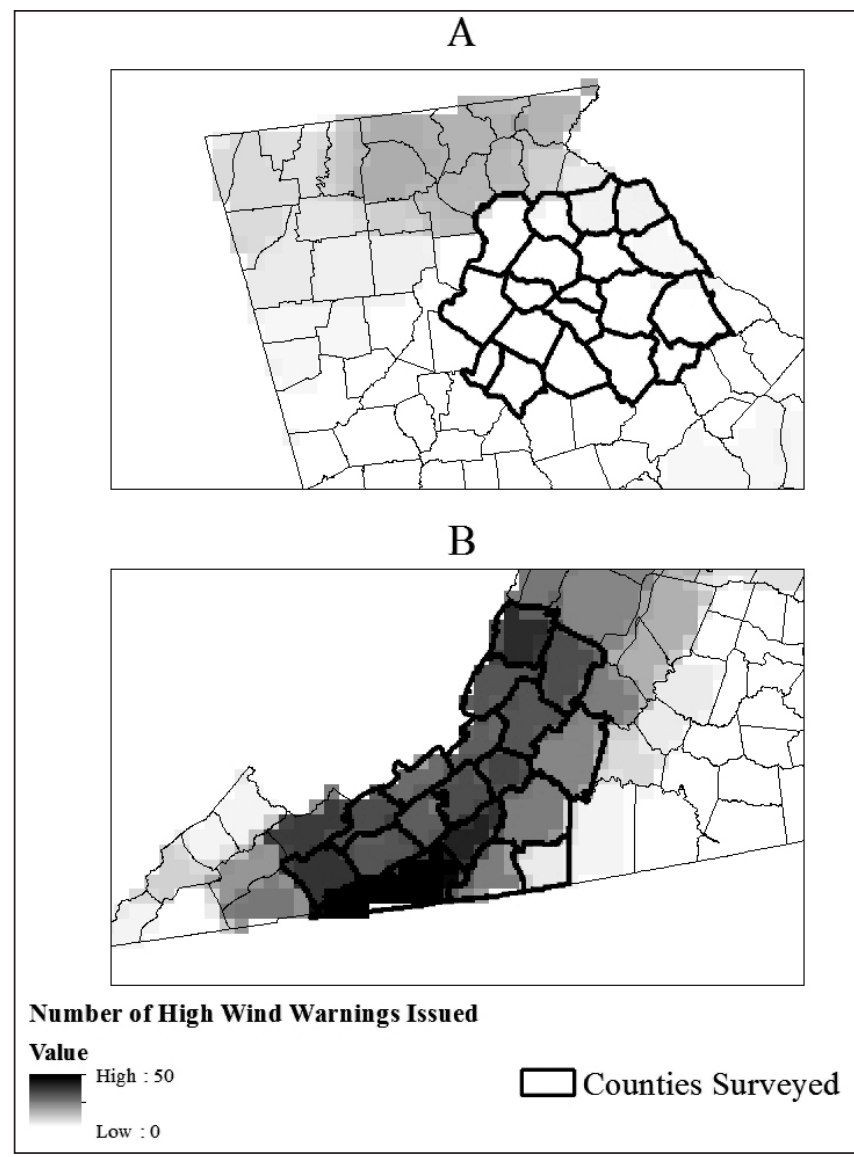

Figure 2. Same as Fig. 1 except focusing on HWWs issued within the survey areas. Boundaries delineate survey respondents' locations in A) GA and B) VA.

for the Roanoke Times were not available, information from the AthensGaWeather blog allowed us to calculate a response rate of $42 \%$ for Georgia users of the blog. Based on previous studies, this statistic falls in the range of average response rates for Internet-based surveys (30-50\%; Greenlaw and Brown-Welty 2009).

\section{b. Survey instrument}

This study focuses on responses to 17 questions from a 38-question online survey that assessed the participants' demographic information, weather information behaviors, familiarity with NWS wind products, and willingness to change plans based on these wind products. The initial survey questions were collaboratively generated by a panel of nonconvective wind experts and graduate students from a variety of fields (psychology, education, statistics, geography, and atmospheric science) and were structured using previous survey research in the atmospheric sciences 


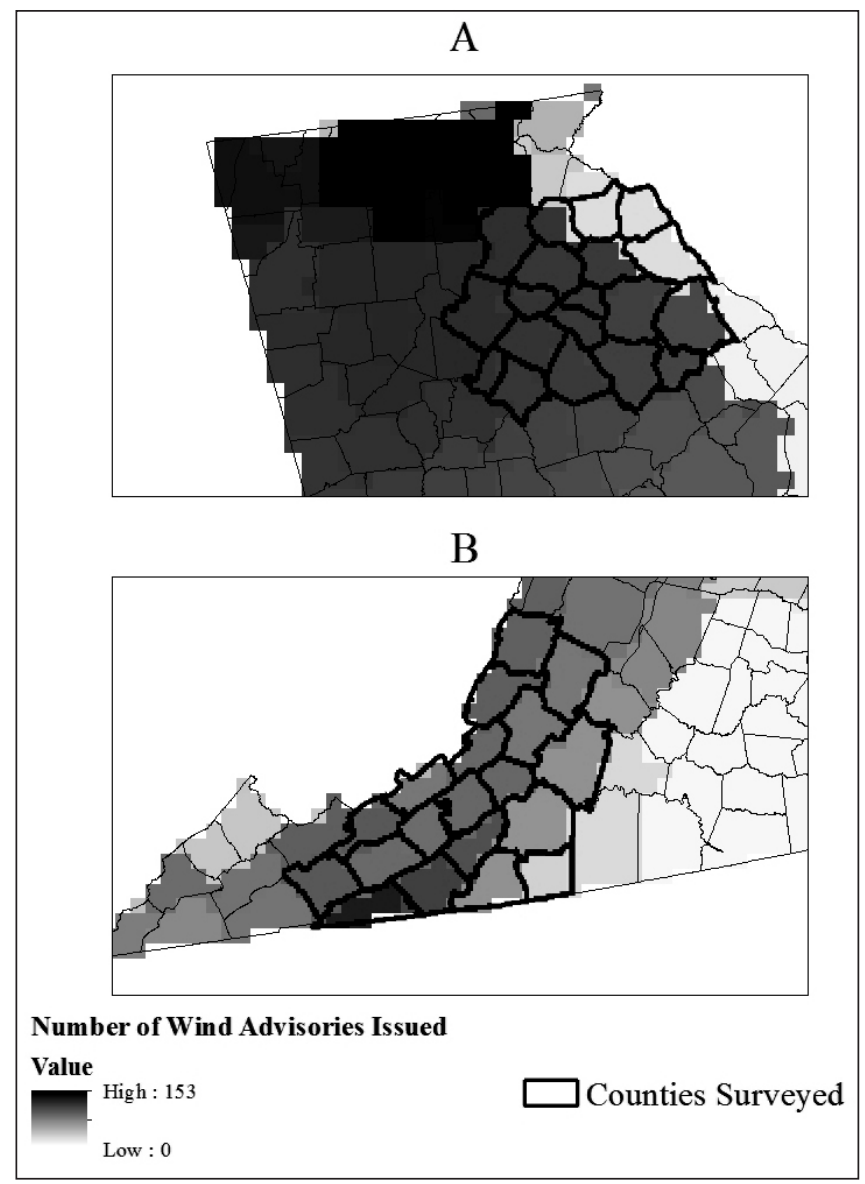

Figure 3. Same as Fig. 2 except focusing on WAs issued within the survey areas. Boundaries delineate survey respondents' locations in A) GA and B) VA.

(Stewart et al. 2016). It was our hope that students not familiar with the atmospheric sciences would be able to point out confusing questions, jargon, and other potential misunderstandings in the survey instrument. The survey questions were then iteratively refined using the expertise of all individuals on the panel. After selecting a final set of questions, members of the panel personally pretested the survey to identify issues with wording and/or grammatical mistakes. These questions were subsequently screened by a social scientist with expertise in survey methods for the atmospheric sciences to identify any potential issues related to framing the questions or the question order (personal communication, Alan E. Stewart, 4 March 2015).

The resulting survey items inquired about the respondents' familiarity with and their definition of two NWS wind products, the WA and HWW. Respondents also were asked to identify the wind threshold that they associated with the issuance of both a WA and an HWW. After determining their personal definitions of

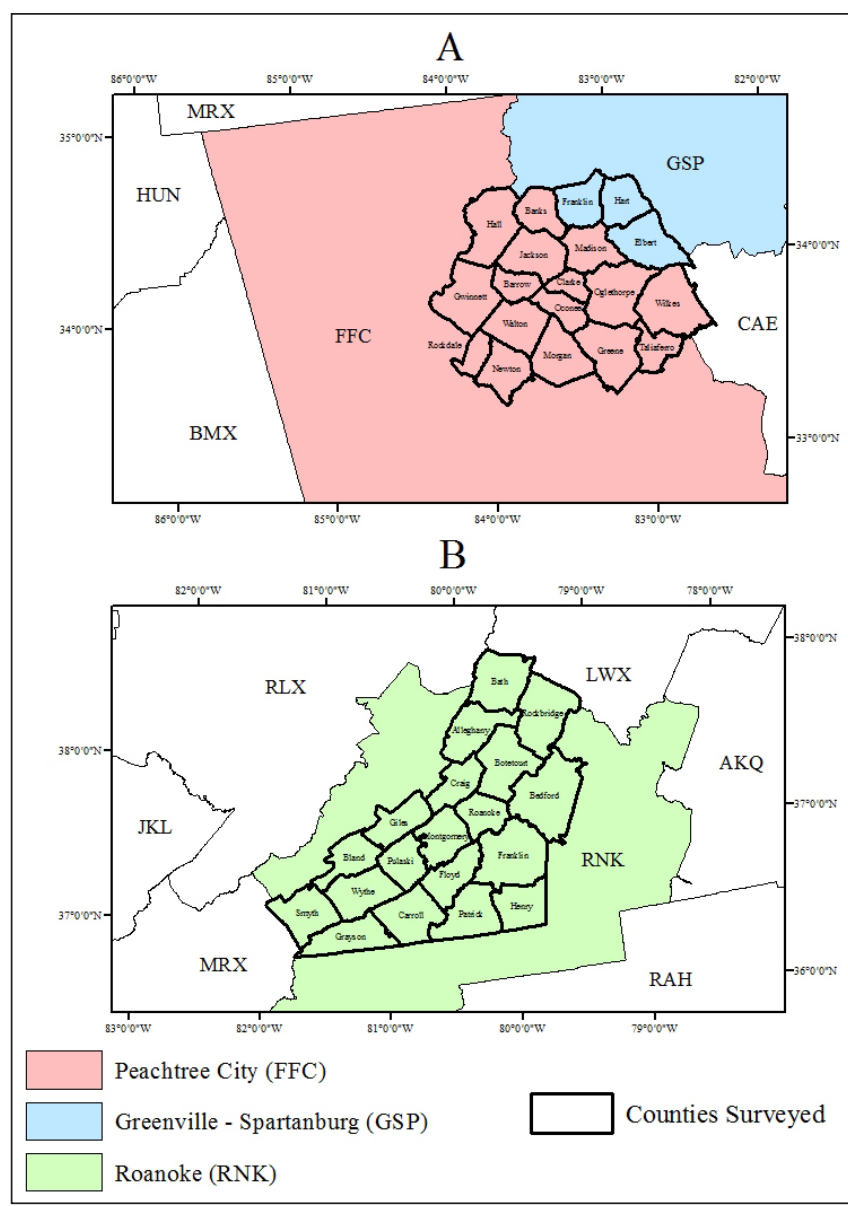

Figure 4. Counties surveyed in this study and National Weather Service county warning areas in A) GA and B) VA.

these wind products, the participants were provided the definitions found in Table 1. The respondents were then asked if the phrasing "wind advisory" and "high wind warning" correctly describes the threat of high winds according to the provided definitions. To quantify their response and/or behavior, the NWS wind product knowledge portion of the survey concluded with a randomized item order question that inquired about the participants' willingness to change their plans based on these products.

To measure weather salience among the survey respondents, seven items were used from the Weather Salience Questionnaire Short Form (Stewart et al. 2012). Although a larger questionnaire exists, the Short Form was used to increase the response rate and reduce fatigue among the survey respondents. All items were measured using a 5-point Likert scale (Likert 1932) ranging from $1=$ strongly disagree to $5=$ strongly agree. An individual's response to each of the items 
in the Weather Salience Questionnaire Short Form was then summed, which resulted in a total score out of 35. [Mean $(M)=27.38$, Standard Deviation (SD) $=3.46]$. In comparison to survey results by Stewart et al. (2012), our sample exhibited significantly more weather salience than the general public $(M=23.275$, $\mathrm{SD}=4.325, \mathrm{t}=22.91, \mathrm{p}=0.00$ ). Example items from the short form include: "I take notice of changes that occur in the weather" and "I am attached to the weather and climate of my hometown." To determine the internal consistency of the measure, a Cronbach's alpha test (Cronbach 1951) was conducted and resulted in an internal consistency of 0.68. Cronbach's alpha statistics can range from 0 to 1 , with higher values indicating greater consistency between the items in the scale. Although previous studies report various acceptable statistics, alphas in the range of $0.65-0.90$ are considered adequate (DeVellis 1991; Tavakol and Dennick 2011).

\section{c. Data analysis}

Descriptive statistics were calculated for the demographic information (gender, age, educational background, and ethnic identification), weather information behaviors, wind speeds that participants associated with WAs and HWWs, and willingness to change plans. To examine differences between groupings associated with demographic variables, the 1-sample t-test (Wilks 2006), 2-sample t-test (Wilks 2006), and chi-square test for independence (Wilks 2006) were calculated to obtain inferential statistics. Content coding (Krippendorff 2004; Hsieh and Shannon 2005) was completed for the open-ended questions involving the definitions of WAs and HWWs. After receiving the open-ended responses, the first author examined the responses and developed thematic categories based on the inductive approach to thematic analysis. Three authors then worked independently to code the responses into these thematic categories. After the initial coding phase, the responses were compared and, if any inconsistencies were observed, the three coders met to decide on the appropriate classification. Responses were first coded into a single category to capture the unique characteristics (i.e., uncertainty phrasing) of an individual's openended answer. However, responses were then coded a second time to address any over-arching themes (e.g., impacts, wind speeds, etc.). The consistency between coders was evaluated using Krippendorff's alpha $(\alpha)$ statistic (Hayes and Krippendorff 2007). This statistic evaluates the consistency between content coders with a numerical result that can vary from 0 to 1 , with higher values indicating more consistency among the raters' thematic categorization of the survey responses. The Krippendorff's alpha statistic for each open-ended question is in the corresponding results section.

\section{d. Participants}

A complete list of demographic information for the 373 participants appears in Table 2. Participants' ages ranged from 18 to 85 years old $(\mathrm{SD}=15.56)$, with a mean age of 42.6 years. When split into categorized age groupings, a fairly even divide is observed; however, the 65+ age group was the least represented $(\mathrm{n}=32$ participants, 8.8\%) compared to the other age groupings in the sample. The sample contained more females $(n=213,57 \%)$, and most of the respondents identified as Caucasian ( $\mathrm{n}=360,94.7 \%)$. Participants were asked to provide their highest degree earned (e.g., some high school, no diploma $=1$ to doctorate degree $=8$ ), with a bachelor's degree being the most represented education category in this sample (M $=5.01, \mathrm{SD}=1.50)$. The females in the sample had a significantly higher educational level $(\mathrm{M}=5.27)$ when compared with the males $(\mathrm{M}=4.78, \mathrm{t}=-3.118, \mathrm{p}=$ $0.02)$. When asked the state in which they reside, $54.8 \%$ $(n=204)$ of the respondents reported living in Georgia with the remaining $45.2 \%(n=169)$ located in Virginia. After examining the weather salience of our sample, a significant difference in the mean score was observed by gender $(p=0.002)$. Males in the sample reported higher weather salience scores $(\mathrm{M}=25.03)$ compared with females $(M=23.46)$. Additionally, a statistically significant difference in mean score also was observed by state $(\mathrm{p}=0.000)$, with residents of Virginia $(\mathrm{M}=$ 24.70) reporting higher weather salience than those living in Georgia $(\mathrm{M}=23.66)$.

We also asked participants to indicate how often they search for weather information, as well as the medium in which they receive that information. Approximately half of the participants reported seeking out weather information multiple times per day, with the remaining participants selecting the other options less frequently (Table 3). Participants indicated they gathered information most frequently from two media (Table 3): smartphone applications $(\mathrm{n}=153,41.0 \%)$ and the Internet $(\mathrm{n}=153,41.0 \%)$. Although this result is not surprising as our announcement and survey were Internet-based, it may confirm the growing trend toward obtaining weather information via mobile 
Table 2. Descriptive statistics for the demographic variables provided by the survey respondents.

\begin{tabular}{|c|c|c|}
\hline Variable & $N$ & $\%$ \\
\hline \multicolumn{3}{|l|}{ Gender: } \\
\hline Female & 213 & 57 \\
\hline Male & 160 & 43 \\
\hline \multicolumn{3}{|l|}{ State: } \\
\hline Georgia & 204 & 54.8 \\
\hline Virginia & 169 & 45.2 \\
\hline \multicolumn{3}{|l|}{ Ethnic Identification: } \\
\hline Caucasian American & 360 & 94.7 \\
\hline Hispanic American & 4 & 1.1 \\
\hline African American & 4 & 1.3 \\
\hline Asian American & 2 & 0.5 \\
\hline Native American & 3 & 0.8 \\
\hline Other (or not reported) & 4 & 1.1 \\
\hline \multicolumn{3}{|l|}{ Educational Background: } \\
\hline Some high school, no diploma & 1 & 0.3 \\
\hline High School Graduate & 12 & 3.2 \\
\hline Some College Credit & 67 & 18.0 \\
\hline Associate Degree & 30 & 8.0 \\
\hline Bachelor Degree & 130 & 34.9 \\
\hline Master's Degree & 87 & 23.3 \\
\hline Professional Degree & 16 & 4.3 \\
\hline Doctoral Degree & 30 & 8.0 \\
\hline \multicolumn{3}{|l|}{ Age Breakdown: } \\
\hline $18-24$ years old & 57 & 15.6 \\
\hline $25-34$ years old & 76 & 20.8 \\
\hline $35-44$ years old & 77 & 21.1 \\
\hline $45-54$ years old & 61 & 16.7 \\
\hline $55-64$ years old & 62 & 17.0 \\
\hline $65+$ years old & 32 & 8.8 \\
\hline
\end{tabular}

and smartphone applications (Demuth et al. 2011). Interestingly, the medium in which the sample obtained weather information was statistically significant ( $p$ $=0.002$ ) by gender, with the males in the sample gathering their information more frequently from nonmobile Internet sources $(n=85,53.1 \%)$ compared to the females' preference for smartphone applications (n $=105,49.3 \%$ ). Please refer to Table 3 for participants' preferred media for receiving weather information. There were no other significant differences observed among the demographic variables.

\section{e. Limitations}

Although the purpose of our analysis is to elucidate the current knowledge of NWS wind products among a sample of weather-salient visitors to a local weather blog, all subsequent results are best interpreted in the context of the following limitations. Although participants were clearly told in the description of the study that they were required to 1) live in either Georgia or Virginia and 2) reside in one of the counties covered by the selected weather blogs, the survey instrument did not provide alternative options for their state and county of residence. This may have resulted in our sample containing individuals living outside of either blog's 
Table 3. Statistics regarding frequency of obtaining weather information and the platform used to obtain that information.

\begin{tabular}{|c|c|c|}
\hline Variable & $N$ & $\%$ \\
\hline \multicolumn{3}{|c|}{ Frequency for Obtaining Weather Information: } \\
\hline Never & 3 & 0.8 \\
\hline 2-3 times a week & 27 & 7.2 \\
\hline 4-6 times a week & 44 & 11.8 \\
\hline Daily & 134 & 35.9 \\
\hline Multiple times per day & 165 & 44.3 \\
\hline \multicolumn{3}{|c|}{ Medium for Obtaining Weather Information: } \\
\hline Social Media & 21 & 5.6 \\
\hline Smartphone Applications & 153 & 41.0 \\
\hline Friends/Family & 3 & 0.8 \\
\hline Television & 22 & 5.9 \\
\hline Internet & 153 & 41.0 \\
\hline NOAA Weather Radio & 3 & 0.8 \\
\hline Other (or not reported) & 18 & 4.9 \\
\hline
\end{tabular}

coverage area. Additionally, the results may have been impacted by order and/or framing effects. The survey instrument revealed the definition of an HWW prior to asking participants about their definition of a WA. This may have resulted in changing their interpretation or perception of the definition and/or wind speeds associated with a WA.

Another concern that arose during the survey process involved getting the participants to focus their perceptions on nonconvective wind events. Even though we notified participants at the top of every survey page to focus on past nonconvective wind experiences, a few respondents still thought of wind situations that were associated with either a severe thunderstorm or tornado. In an attempt to focus on wind-specific products and avoid referencing convective events, we used the behavioral response of visiting a weather blog as a proxy for weather salience. By reducing our sample to those who regularly obtain weather information via weather blogs, we lose the ability to generalize about the public. However, recall that our convenience sample (i.e., the participants who were easy to reach) scored higher on the weather salience measure $(\mathrm{M}=$ 27.38) than the general public $(M=23.28$; Stewart et al. 2012). Therefore, if our sample misinterpreted these wind products and the meteorological settings they reference, then one may hypothesize that the general public would as well.

Lastly, a level of trust associated with the NWS, a government organization, could have impacted whether an individual truly believed that the current phrasing warns for the impending wind hazard. To combat this predetermined level of trust, future studies involving nonconvective wind product definitions and phrasing should be presented without an affiliation to determine if the wording truly warns for the given threat. Given the absence of research examining the public's threat perceptions of nonconvective wind events, future studies should compare these events with those that are convective in nature.

\section{Results}

\section{a. Familiarity with NWS wind products}

The first portion of this analysis seeks to understand a participant's familiarity with NWS wind products and the wind speeds they associate with them. To determine their exposure to the wind products, each participant was asked: "Have you ever heard of a High Wind Warning (Wind Advisory) that is issued by the National Weather Service?" Most of the survey participants had previously encountered both wind products, with the WA $(\mathrm{n}=343,92 \%)$ being more well-known compared to the HWW ( $\mathrm{n}=337,90.3 \%)$. Differences among 
participants by region also were statistically significant, with more participants in Virginia having heard of both HWWs ( $\mathrm{n}=163$, 96.4\%; Chi-square: 13.191, $\mathrm{p}=0.00$ ) and WAs ( $\mathrm{n}=161,95.3 \%$; Chi-square: $4.575, \mathrm{p}=0.03$ ), compared to Georgia respondents (HWW: $\mathrm{n}=174$ $85.3 \%$; WA: $\mathrm{n}=182,89.2 \%$ ).

To assess the perceived wind speed threshold for product issuance, participants were directed to give a numerical response when asked: "How fast do you think the winds need to be for a High Wind Warning (Wind Advisory) to be issued for your area?" For an HWW, the mean wind speed across the entire sample was $17 \mathrm{~m} \mathrm{~s}^{-1}(38 \mathrm{mph})$, and the mean wind speed for a WA was $12.5 \mathrm{~m} \mathrm{~s}^{-1}$ (28 mph; Fig. 5). The mean wind speed varied by geographic location for both wind products, with participants in Virginia providing a higher mean wind speed for both an HWW $(\mathrm{M}=18.3$ $\left.\mathrm{m} \mathrm{s}^{-1}, \mathrm{p}=0.00\right)$ and a WA $\left(\mathrm{M}=13 \mathrm{~m} \mathrm{~s}^{-1}, \mathrm{p}=0.06\right)$ compared to respondents in Georgia. For more statistics on perceived wind speeds and a comparison between geographic locations, see Fig. 5.

A closer examination of Fig. 5 reveals that HWW responses from both Georgia and Virginia resemble the minimum sustained wind speed required for the product to be issued by their local WFO $\left(17.9 \mathrm{~m} \mathrm{~s}^{-1}\right)$. The Virginia participants likewise provided WA responses that also modeled the local issuance threshold $(13.8 \mathrm{~m}$ $\mathrm{s}^{-1}$ ), whereas the Georgia participants overestimated the minimum sustained WA threshold $\left(8.9 \mathrm{~m} \mathrm{~s}^{-1}\right)$. Framing and order effects may have bounded the Virginia participants' perception of the WA threshold, possibly aiding their more accurate responses. In addition, framing and ordering effects may have biased the Georgia responses toward higher WA values. After the Georgia participants learned they had underestimated the HWW threshold (as the majority of these respondents did), they may have been more inclined to report higher WA thresholds than they otherwise would have. However, if the participants perceived HWWs and WAs to be defined by wind gusts, then individuals from both states underestimated the wind speed criteria for issuing both products in all three WFOs. For further comparison, please see Table 4 for the thresholds of product issuance in the Georgia and Virginia WFOs and Fig. 5 for statistics on participants' reported wind speeds for product issuance.

\section{b. Definition of NWS wind products}

To evaluate the participants' definitions of the NWS wind products, survey participants provided an

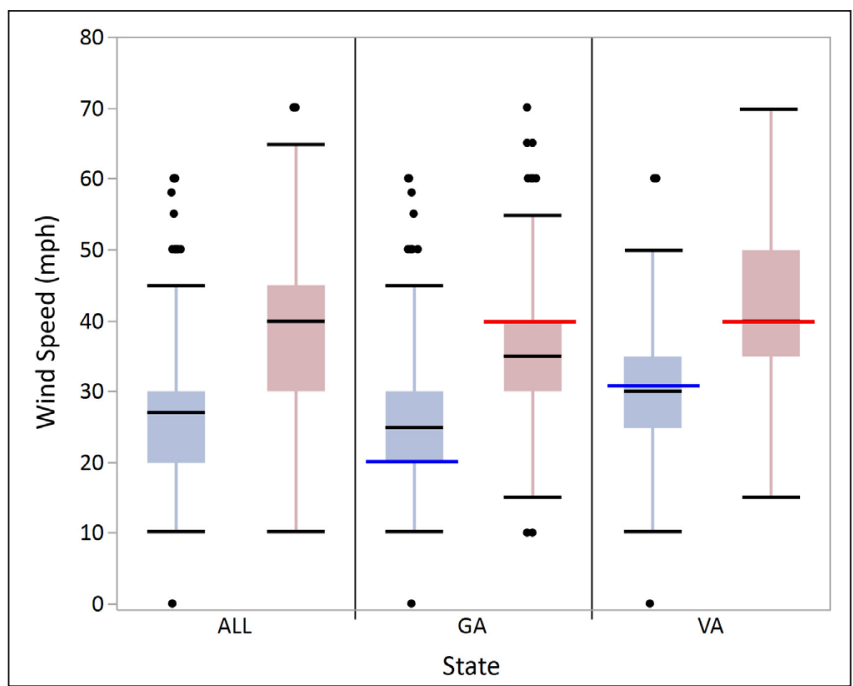

Figure 5. The distribution of perceived wind speeds for both a WA (light blue) and an HWW (pink) in GA and VA. For comparison with the NWS WFO's product issuance criteria, the minimum wind thresholds (i.e., sustained winds) have been plotted for both a WA (blue line) and an HWW (red line). The dots represent survey participants who reported a wind speed a lot higher or a lot lower than normal (outliers). If more than one participant reported the same outlier, then the dots were placed side by side. Note: The median wind speed (mph) for the state of VA (41 mph or $\left.18.33 \mathrm{~m} \mathrm{~s}^{-1}\right)$ is just above the threshold for HWW issuance $(40 \mathrm{mph}$ or $\left.17.88 \mathrm{~m} \mathrm{~s}^{-1}\right)$.

open-ended response to the question: "What does a High Wind Warning (Wind Advisory) mean to you"? The authors independently coded the responses into one of six different themes (Table 5). The overall intercoder relationship was good for both the definitions associated with HWWs (Krippendorff's $\alpha=0.953$ ) and WAs (Krippendorff's $\alpha=0.963$ ). The content-coded themes, examples, and frequency of occurrence in the sample are shown in Table 5.

The first thematic category captured responses that described NWS wind products in terms of the impacts that a participant anticipated experiencing. Responses were content-coded as an impact-based definition when an individual discussed various ways the wind would either impact themselves (e.g., difficulty driving) or the environment around them (e.g., fallen trees and limbs, patio furniture thrown about, etc.). This was the most frequent response $(42.4 \%)$ given as a definition for an HWW. For example, the following definition was coded to this theme: "Be careful of low lying limbs or trees that could break onto property or roads. Possible 
Table 4. Issuance criteria for NWS wind advisories and high wind warnings in $\mathrm{m} \mathrm{s}^{-1}(\mathrm{mph})$ for surveyed counties in GA and VA. Thresholds for GA and VA were provided by NWS Peachtree City, GA; NWS Greenville-Spartanburg, SC; and NWS Blacksburg, VA.

\begin{tabular}{|c|c|c|}
\hline Location & Sustained & Gusts \\
\hline High Wind Warning: & & $\geq 25.9 \mathrm{~m} \mathrm{~s}^{-1}(58 \mathrm{mph})$ \\
\hline NWS Peachtree City & $\geq 17.9 \mathrm{~m} \mathrm{~s}^{-1}(40 \mathrm{mph})$ & $\geq 25.9 \mathrm{~m} \mathrm{~s}^{-1}(58 \mathrm{mph})$ \\
\hline NWS Greenville-Spartanburg & $\geq 17.9 \mathrm{~m} \mathrm{~s}^{-1}(40 \mathrm{mph})$ & $\geq 25.9 \mathrm{~m} \mathrm{~s}^{-1}(58 \mathrm{mph})$ \\
\hline NWS Blacksburg & $\geq 7.9 \mathrm{~m} \mathrm{~s}^{-1}(40 \mathrm{mph})$ & \\
\hline Wind Advisory: & & $\geq 15.6 \mathrm{~m} \mathrm{~s}^{-1}(\geq 35 \mathrm{mph})$ \\
\hline NWS Peachtree City & $8.9-15.6 \mathrm{~m} \mathrm{~s}^{-1}(20-35 \mathrm{mph})$ & $\geq 15.6 \mathrm{~m} \mathrm{~s}^{-1}(\geq 35 \mathrm{mph})$ \\
\hline NWS Greenville-Spartanburg & $\geq 15.6 \mathrm{~m} \mathrm{~s}^{-1}(\geq 35 \mathrm{mph})$ & $20.5-25.5 \mathrm{~m} \mathrm{~s}^{-1}(46-57 \mathrm{mph})$ \\
\hline NWS Blacksburg & $13.8-17.4 \mathrm{~m} \mathrm{~s}^{-1}(31-39 \mathrm{mph})$ & \\
\hline
\end{tabular}

power outages." However, for a WA, roughly onefourth of the respondents provided an impact-based definition. Similar to the HWW, an example definition classified into this category is: "...winds may cause minor inconveniences, such as small limbs falling and unsecured objects may be strewn about, but does not represent a threat to life or property."

The second category included responses describing the wind speed thresholds associated with each product. These responses were coded when an individual mentioned only wind speeds or insinuated that a certain speed threshold must be satisfied prior to wind product issuance. This was the second most frequent response (23.7\%) for the definition of an HWW, with a typical response from this thematic category being: "Wind gusts over 57 miles per hour and sustained winds over 35 miles per hour." Alternatively, this was the third most frequent response for a WA, with $20.1 \%$ of the sample giving a definition solely involving wind speeds. An example definition for this category was: "Sustained winds of $15 \mathrm{mph}$ with gusts topping $25 \mathrm{mph}$."

The third content-coded theme for NWS wind product definitions involved a combination of both impacts and wind speed thresholds. Definitions in this category differed from the previous classifications because they contained components from an impactbased definition but also emphasized that a specific wind speed or threshold is necessary for the issuance of the wind products. For an HWW, fewer than 10\% of survey respondents provided a definition involving both impacts and wind speeds. A clear example of this category was: "Wind gusts of over $50 \mathrm{mph}$ may occur, which may cause trees or large limbs to fall down. And even more importantly, driving could become dangerous, particularly where crosswinds are prevalent." When describing a WA, only a limited percentage of the participants $(2.7 \%)$ used both impacts and wind speeds to define this product. Like the previous example, for a WA the following was classified into this category: "Specifically, winds above 30-35 mph sustained or gusts higher than $40 \mathrm{mph}$ that can cause some branches to come down, limited power outages, and an impairment to drivers of high profile vehicles."

The fourth theme captured responses involving a temporal component. The responses were coded into this category when a participant described high winds as "currently going on," "occurring," "reported in the area," "observed," or other temporal phrasings. It should be noted that if an individual mentioned a temporal aspect of the definition along with either impacts or a wind-speed threshold, the temporal component took priority. Given the abundance of impact- and speedbased definitions, it was judged best to highlight the unique temporal component of definitions whenever it existed. The temporal definition was the least common content categorization for both an HWW (6.8\%) and a WA $(0.8 \%)$. An example of common phrasing associated with this category is: "Wind gusts are expected during the given period of time."

The fifth category was developed for responses communicating the probability or uncertainty that high winds would occur. Responses were assigned to this category when a participant described high winds as "probable," "with potential to develop," "may happen," "are a possibility," "a chance," or other phrases implying uncertainty. Like the temporal 
Table 5. Thematic categories, examples, and frequency of occurrence for the survey respondents' definitions of high wind warning (HWW) and wind advisory (WA).

\begin{tabular}{|c|c|c|c|}
\hline Theme of Definition & Example & $\begin{array}{l}\text { HWW } \\
\text { N (\%) }\end{array}$ & $\begin{array}{c}\text { WA } \\
\text { N }(\%)\end{array}$ \\
\hline $\begin{array}{l}\text { 1. Impacts: } A \text { definition of high winds } \\
\text { with the potential/observed impacts } \\
\text { they will cause. }\end{array}$ & $\begin{array}{l}\text { "Winds are high enough to } \\
\text { cause hazards to driving and } \\
\text { can cause debris to be blown } \\
\text { into the air, also causing a } \\
\text { hazard" }\end{array}$ & $158(42.7)$ & $85(23.2)$ \\
\hline $\begin{array}{l}\text { 2. Wind Speeds: A definition of high } \\
\text { winds using a specific wind speed } \\
\text { threshold or mentioning the need for } \\
\text { a wind speed threshold to be met } \\
\text { prior to product issuance. }\end{array}$ & $\begin{array}{l}\text { "Winds are expected to gust } \\
\text { higher than } 40 \mathrm{mph} . "\end{array}$ & $88(23.7)$ & $73(20.1)$ \\
\hline $\begin{array}{l}\text { 3. Impacts and Wind Speeds: } A \\
\text { definition of high wind using both } a \\
\text { wind speed threshold and the } \\
\text { potential/observed impacts. }\end{array}$ & $\begin{array}{l}\text { "Winds that are under } 40 \mathrm{mph} \\
\text { that have the potential to cause } \\
\text { damage to property." }\end{array}$ & $30(8.2)$ & $10(2.7)$ \\
\hline $\begin{array}{l}\text { 4. Temporal: } A \text { definition of high } \\
\text { winds using phrasing that indicates } \\
\text { that winds are currently going on, } \\
\text { occurring, reported in the warning } \\
\text { period, observed, etc. }\end{array}$ & $\begin{array}{l}\text { "High winds are occurring and } \\
\text { may occur in my area." }\end{array}$ & $25(6.8)$ & $3(0.8)$ \\
\hline $\begin{array}{l}\text { 5. Uncertainty: } A \text { definition of high } \\
\text { winds using phrasing that indicates } \\
\text { winds are probable, have the } \\
\text { potential to occur, may happen, are a } \\
\text { possibility, etc. }\end{array}$ & $\begin{array}{l}\text { "Possible chance of high } \\
\text { winds that can do damage to } \\
\text { property." }\end{array}$ & $31(8.4)$ & $124(34.1)$ \\
\hline $\begin{array}{l}\text { 6. Watch Criteria: } A \text { definition was } \\
\text { considered watch criteria if it } \\
\text { mentioned anything about the } \\
\text { potential to occur or conditions are } \\
\text { favorable for the development of } \\
\text { winds, etc. }\end{array}$ & $\begin{array}{l}\text { "Conditions are favorable to } \\
\text { become windy." }\end{array}$ & $4(1.3)$ & $77(23.2)$ \\
\hline $\begin{array}{l}\text { 7. General: } A \text { definition of high winds } \\
\text { using non-specific phrasing }\end{array}$ & $\begin{array}{l}\text { "Evening excursions will be } \\
\text { quite brutal." }\end{array}$ & $38(10.2)$ & $70(19.1)$ \\
\hline
\end{tabular}


category, this theme was prioritized above phrasing relating to impacts or wind speeds to capture the unique responses addressing uncertainty. Only a small portion of the survey respondents defined an HWW with words or phrases involving uncertainty. An example includes such phrasing as: "Possible chance of high winds that can do damage to property." However, this was the most frequent category (34.1\%) associated with WA definitions. A straightforward example of this category for a WA is: "Potential for high winds. Be advised." Further, if a definition mentioned the "potential for winds," "favorable conditions," the "chance of occurrence," etc., then their definition was also coded as "Watch" criteria. Because the definition of a high wind watch was specifically not elicited from the participants, the authors chose to explore the responses to determine whether any characteristics of watch products were observed in the respondents' definitions. When describing an HWW, only four participants provided a definition that contained language consistent with a high wind watch $(n=4,1.3 \%)$; however, $23 \%$ of participants used this phrasing to define a WA.

The final content-coded category involved nonspecific definitions. This general category was developed from survey responses that lacked specificity (e.g., high winds, increased winds today, dangerous winds, etc.). About $10 \%$ of the survey respondents provided definitions for an HWW that were coded into this category, with a sample response being: "Dangerous high winds." Slightly $<20 \%$ of the respondents' WA definitions fit in the general category, with a representative definition involving this theme being: "It's going to be quite windy."

The first analysis, described above, incorporated a mutually exclusive coding scheme to capture the specific components (e.g., temporal, uncertainty, etc.) of a respondent's wind product definition; therefore, some responses containing impact- and speed-based language were not recorded as such. Thus, a separate coding scheme was created and an additional analysis was performed using only the impacts, wind speed thresholds, and a combination of the two themes (impacts and wind speeds). If a response did not fit into one of those three categories, it was coded as "None." Most participants gave a definition involving impacts for both an HWW (57.5\%) and a WA (31.8\%), with more than one-fourth of the respondents providing definitions involving wind speeds or a threshold for both wind products. A statistically significant difference was observed for gender relating to the definition of both wind products. Female respondents focused on the impacts associated with both a WA (Chi-square: 12.88, $\mathrm{p}=0.01$ ) and an HWW (Chi-square: 13.91, $\mathrm{p}=$ 0.003 ), but more male participants provided a definition associated with wind speed thresholds.

\section{c. Change in plans based on NWS wind products}

Survey respondents also were asked to provide information on the likelihood that wind product issuance would alter their plans. To gauge this tendency, respondents were asked: "On a scale of 1 (extremely unlikely) to 10 (extremely likely), how likely are you to change your plans given a wind advisory, high wind watch, and high wind warning?" Individuals in the sample were less likely to change their plans for a WA $[\mathrm{M}=2.75$, Median $(\mathrm{Mdn})=2, \mathrm{SD}=2.10]$, compared to both a high wind watch $(\mathrm{M}=3.78, \mathrm{Mdn}=3, \mathrm{SD}=$ $2.27)$ and an HWW $(\mathrm{M}=8.86, \mathrm{Mdn}=10, \mathrm{SD}=2.57)$. To further explore this relationship, the frequency distributions for the likelihood of changing their plans for a high wind watch and WA are shown in Fig. 6 . These distributions reveal that more participants ( $\mathrm{n}=$ $125,33.8 \%$ ) were extremely unlikely to change their plans in the event that a WA was issued for their area. However, an internal comparison of each individual's responses shows that $57 \%(n=210)$ of the participants were more likely to alter their plans for a high wind watch than a WA. The remaining respondents were either equally likely $(\mathrm{n}=130,35.2 \%)$ or less likely ( $\mathrm{n}$ $=29,7.8 \%$ ) to modify their plans when a high wind watch was issued for their area, compared with a WA. No significant differences were observed among the demographic variables.

\section{d. Phrasing of NWS wind products}

To examine whether the phrasing of the NWS wind products successfully warns for the hazard associated with both a WA and an HWW, the survey respondents were given the definition of both NWS wind products and asked: "Do you think the phrasing "High Wind Warning" (Wind Advisory) warns of the wind threat described above? If No, what phrasing would you suggest in the place of High Wind Warning (Wind Advisory)?" Overall, most of the survey respondents (n $=329,88.2 \%$ ) believed that the phrasing "High Wind Warning" addressed the appropriate hazards. However, the remaining participants provided some alternative wordings that would alert them to the appropriate level of threat. The most frequent response for an alternative 


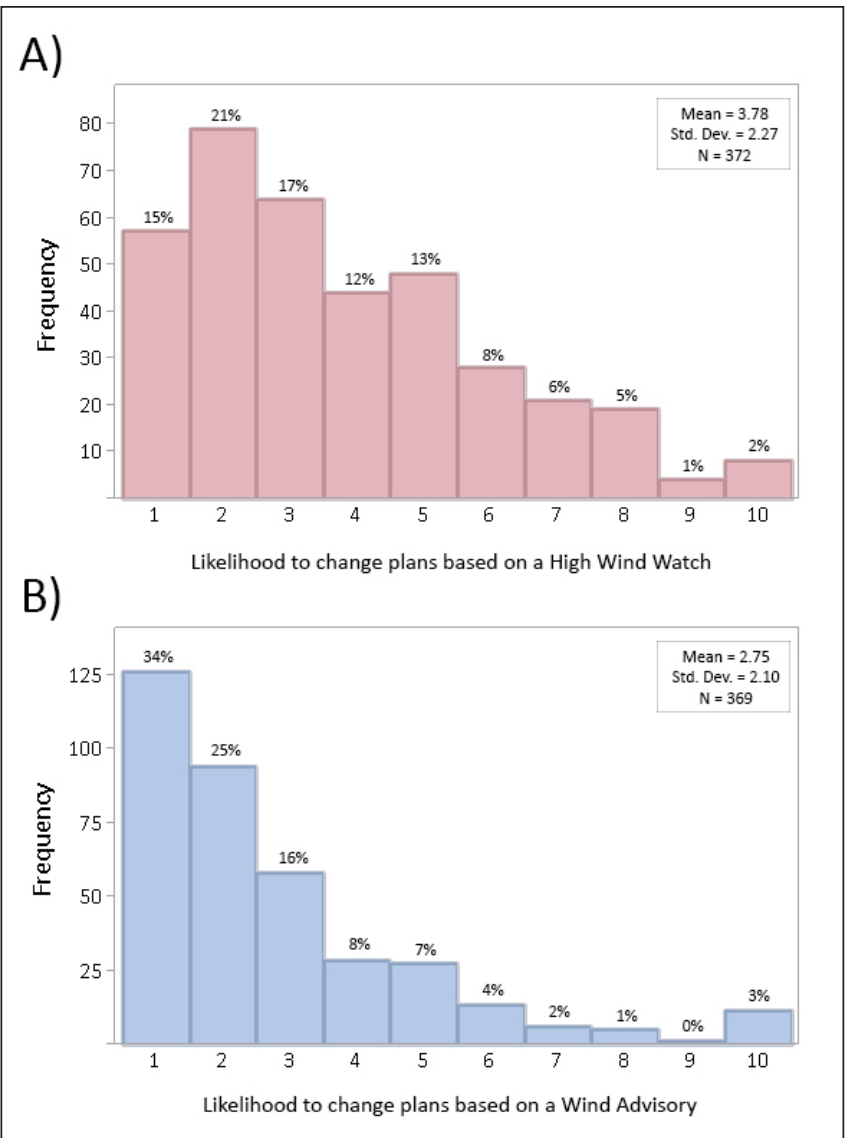

Figure 6. The frequency distributions for an individual's likelihood to change their plans based on A) a high wind watch and B) a WA. Likelihood is measured on a Likert scale (Likert 1932) from 1 (extremely unlikely) to 10 (extremely likely).

phrasing was both: "Dangerous Wind Warning" and "Severe Wind Warning" with 9 participants each suggesting that new phrasing. The second most frequent result was "Damaging Wind Warning" $(n=4)$. Some additional suggestions provided by participants acknowledged that "High" is a subjective term, but perhaps "Severe" could be used to communicate the potential for damaging winds. For the complete list of HWW alternative phrasings, see Table 6.

The same question was asked to gain a better perspective on the phrasing of "Wind Advisory." Similar to the HWW, a large portion of the participants $(\mathrm{n}=$ $320,85.8 \%$ ) believed that the current phrasing correctly advises of the existing or impending threat of wind. Individuals who did not agree provided suggestions and alternatives. The most frequent suggestion $(\mathrm{n}=$ 8) was to replace a "Wind Advisory," with a "High Wind Advisory." Even though a majority of the sample could relate to these wind products, a few individuals stated that they "...find it easy to confuse 'watch' with 'advisory', despite knowing some basic weather info" or that "the definition or phrase should address both sustained winds and gusts." Overall, those who suggested alternatives believed that the term "Wind Advisory" is simply "...very vague and not really cause for alarm." For a complete list of WA alternatives, please see Table 6 .

\section{Discussion}

\section{a. Impact-based definitions}

Sections $3 \mathrm{a}$ and $3 \mathrm{~b}$ clearly reveal that, on average, participants in our sample had previously heard of both a WA $(\mathrm{n}=343,92 \%)$ and an HWW $(\mathrm{n}=337,90.3 \%)$. Although the participants did recognize that an HWW communicated more intense wind speeds than a WA, their wind speed perceptions for product issuance must be considered in terms of both sustained winds and gust criteria. As described in section $3 \mathrm{a}$ and Fig. 5 , participants reported wind speeds that resembled the minimum (i.e., sustained wind criteria) HWW and WA criteria. However, if they were reporting gusts, then they generally associated substantially weaker wind speeds with NWS product issuance than the official thresholds. In a related vein, recent research by Miller et al. (2016a) concluded that $>70 \%(25 \%)$ of all injury-causing and fatal events occurred below the HWW (WA) gust threshold (Table 4) and empirically suggested a gust criterion of " 15.6 and $21.0 \mathrm{~m} \mathrm{~s}^{-1}$ ( 35 and $47 \mathrm{mph}$ ) for the wind advisory and high wind warning, respectively." Thus, the wind speeds reported by the respondents, whether interpreted as sustained winds or gusts, appear to align more closely with observed impact-causing wind speeds as described in Miller et al. (2016a). With recent studies revealing that humans overestimate wind speed observations by roughly one-third (Agdas et al. 2012; Miller et al. 2016b), these reports, as Miller et al. (2016b) concluded, may "contribute to the incorrect verification of a wind-related warning." Therefore, lowering the threshold of wind product issuance may bring impact-causing wind speeds, thresholds for product issuance, and individuals' sustained/gust wind speed perceptions into better alignment. Prior to adjusting the threshold of product issuance, additional research is needed to better understand the implications of increasing the frequency of nonconvective wind products (i.e., perceived false alarm ratio) and how this may affect an individual's behavioral intentions to 
Table 6. A list of alternative phrasings, ordered by frequency, for both an HWW and WA provided by survey respondents.

\begin{tabular}{|c|c|}
\hline High Wind Warning & Wind Advisory \\
\hline & \\
Dangerous Wind Warning $(n=9)$ & High Wind Advisory $(n=8)$ \\
Severe Wind Warning $(n=9)$ & High Wind Watch $(n=3)$ \\
Damaging Wind Warning $(n=4)$ & High Wind Warning $(n=3)$ \\
Extreme Wind Warning $(n=2)$ & Strong Wind Advisory $(n=3)$ \\
Deathly Wind Warning $(n=1)$ & Wind Warning $(n=3)$ \\
Sustained High Wind Warning $(n=1)$ & High Wind Alert $(n=2)$ \\
High Wind Danger $(n=1)$ & Potential Wind Damage Advisory $(n=2)$ \\
Hazardous Wind Warning $(n=1)$ & Elevated Winds $(n=1)$ \\
Strong Wind Warning $(n=1)$ & Gust Warning $(n=1)$ \\
Highly Active Wind Warning $(n=1)$ & Wind Caution $(n=1)$ \\
Extreme High Wind Warning $(n=1)$ & Moderate Wind Warning $(n=1)$ \\
& \\
\hline
\end{tabular}

perform a protective action (see Miller et al. 2016a for further discussion).

When asked to define the wind products, a large proportion of participants discussed an HWW and a WA in terms of impacts to the environment and/or personal impacts that they would experience. Upon further examination, our results revealed a significant difference in the way that males and females define these wind products (HWW: $\mathrm{p}=0.003$, WA: $\mathrm{p}=$ 0.01). Male respondents were significantly more likely to define these products in terms of wind speeds and/or thresholds for product issuance, but females more strongly identified with personal impacts from high winds. These results are consistent with risk communication studies in the healthcare field, where the presentation of medical and drug information is largely focused on the male's "...preference for data and evidence" (Hugman 2015). However, this datadriven display of risk information fails to incorporate the "...psychological, social, domestic, and spiritual aspects of safety" that are often favored by women (Hugman 2015). These gender-specific preferences for receiving risk information likely explain the female's (male's) impact-based (speed-based) interpretation of these high wind products. Even though these gender differences exist, we also must consider the overall trend of respondents to define these high wind products in terms of impacts. This result echoes the efforts of several organizations (NWS 2015d; UK Met Office 2016) to provide impact-related information when communicating about potential weather hazards.

The NWS's experimental impact-based warning system initiative has begun exploring the integration of threat and impact-based information into several selected WFOs' text products when a severe thunderstorm or tornado product is issued (NWS 2015d). On the other hand, the United Kingdom (UK) Met Office has already integrated impact-based warning information into their weather alerts to the general public (UK Met Office 2016). Other researchers have examined the addition of impact-based information to convective warning products and revealed interesting results that could be applicable to nonconvective wind products. Although the impact from nonconvective winds can vary substantially from a convective event (e.g., a tornado), perhaps similarities can be drawn between the two hazards. Ripberger et al. (2015) discovered that survey participants in tornado-prone areas were more likely to take protective action when impact-based information was included in the warning text for convective hazards. Our results from section $3 \mathrm{~b}$ suggest that individuals may exhibit similar tendencies because of the number of respondents who defined these wind products using impact-related information. However, Ripberger et al. (2015) also noted that the use of impact-based information was only successful to a certain degree. The authors explained that increasing the intensity of stormrelated impact information "prompt[ed] decreases in the probability that respondents would shelter in place and increases in the probability that respondents 
would leave their residences for a safer location." If this is indeed true, all WFOs should strongly consider language intensity when providing 1) relatable impacts (e.g., lawn furniture will blow away, trees may fall, plants may topple, etc.) that an individual would likely experience and 2) recommended actions (e.g., secure your lawn furniture, bring in your plants, avoid driving if possible, etc.) that an individual would likely perform during a high wind event. Additionally, several survey respondents provided alternative phrasings that involved impact-based information. Most of the suggestions altered the word "high" in HWW, and replaced it with a descriptive adjective for the type of impact they may observe (e.g., dangerous wind warning, severe wind warning, damaging wind warning, etc.). Although these changes would more clearly communicate potential impacts, it also could cause inconsistencies and/or influence the "spectrum of comprehension [associated with] the current watch/warning/advisory system" (Eastern Research Group 2014).

\section{b. A comparison of watch versus advisory}

With previous research (Eastern Research Group 2014; NWS 2015e) suggesting that misinterpretations of the watch/warning/advisory system exist among the general public, this study and the following discussion attempt to discern whether this also occurs with nonconvective wind products. Although a majority of our sample reported having previously heard of both an HWW and a WA, section $3 \mathrm{~b}$ of the results reveals that our sample had difficulty differentiating the high wind products in terms of likelihood. Only a few participants defined an HWW using terminology commonly associated with a high wind watch. However, when describing a WA, $23.2 \%$ of the sample used words and/ or phrases commonly found in a weather watch product (e.g., "conditions are favorable"). Similarly, in section $3 \mathrm{c}$ of the results and Fig. 6, more individuals reported that they would change their plans for a high wind watch compared to a WA. These findings may indicate that participants 1) perceive less certainty with a WA and believe it to be the product issued during the least hazardous wind conditions akin to a weather watch product or 2) believe that the WA is a natural extension of the high wind watch, which may not prompt any additional preparedness action. These interpretations could be due to several issues, including some we posit here: 1) the language commonality using the word "high" with both a high wind watch and an HWW, or 2) the word "advisory" may simply connote less certainty and/or evoke the same level of threat as a weather watch product.

The alternative phrasings that survey respondents provided, discussed in section $3 \mathrm{~d}$ of the results and Table 6, can offer insight into the similarity in phrasing associated with both a high wind watch and an HWW. When asked to provide an alternative to the phrasing "wind advisory," the most popular response was a "high wind advisory." Perhaps the commonality among all the products allows for a more precise perception of threat and a smooth transition between the products. Interestingly, according to the NWS a "high wind advisory" already exists and is: "...issued by the National Weather Service when high wind speeds may pose a hazard." The criteria for this advisory varies from state to state. For example, in Michigan, the advisory criteria are sustained nonconvective winds $\geq 13.4 \mathrm{~m} \mathrm{~s}^{-1}$ (30 mph) lasting for at least 1 hour or winds $\geq 20.1 \mathrm{~m}$ $\mathrm{s}^{-1}$ (45 mph) for any duration (NWS 2015a). Although this product exists, we could not find any evidence of the product's issuance in the last 10 years (Iowa Environmental Mesonet 2015). Future studies should examine whether adding the word "high" into the current WA product would allow the general public to better understand the upgrading/downgrading process and the correct threat level associated with each wind product.

Another possibility for the observed misinterpretation of threat level and/or probability of occurrence by roughly $20 \%$ of the sample could be due to the use of the word "advisory." Currently, the NWS is embarking on the Hazard Simplification Project that aims to examine the known issues with the current watch/ warning/advisory system and to implement improved risk communication when discussing potential weather hazards (Eastern Research Group 2014; NWS 2015e; Eastern Research Group 2016). They have conducted several focus groups with members of the general public, emergency managers, and broadcast meteorologists to better understand the current knowledge and concerns associated with issuing severe weather products. Initial results reveal that interpretations of these terms can vary widely, with the word "advisory [being] generally misunderstood" (NWS 2015e). Although the Hazard Simplification Project has only considered convective products, the need exists to examine all hazards. Are the wind products just another example of the term "advisory" being generally misunderstood? This study provides empirical evidence that the "spectrum of comprehension" (Eastern Research Group 2014) also 
exists among the NWS wind products; however, we do not have an explanation for this array of understanding and/or whether it is a direct result of the language associated with the NWS wind products. Therefore, researchers should further investigate 1) whether "advisory" also is being misunderstood in the context of wind products, 2) if language inconsistency between WA and high wind watch/warning alters the perception of threat, and 3) if knowing the correct product definition would improve awareness and/or willingness to take a protective action.

\section{Conclusions}

The current NWS wind products, although familiar among our sample of weather-salient participants, generally focus on a numerical wind speed threshold instead of the impacts that an individual will experience. Although requisite wind speeds may be a necessary component of the product's issuance criteria and were reasonably depicted by our weathersalient sample (given the framing and order effects), our results indicate that this numerical approach for defining nonconvective wind hazards was not preferred by all respondents. Instead, a statistically significant difference by gender was observed relating to the definition of both wind products. Female respondents focused on the impacts associated with high wind events, but more male participants provided a definition associated with wind speed thresholds. A similar trend is observed in the healthcare field (Hugman 2015), which leads to these challenging questions for the weather enterprise: can and should weather risk information be tailored to an individual? Overall, our study revealed that participants identified with the potential hazards and impacts more than potential wind speeds. Although a movement focused on including more impactrelated product information and phrasing may seem appropriate, additional research must 1) ensure that the term "impact" is consistent between meteorologists and the general public (Eastern Research Group 2016) and 2) determine, with certainty, that meteorological impacts can be estimated ahead of an event. Otherwise, this additional information may only introduce further complications.

Additionally, our survey revealed that respondents reported being more likely to alter their plans for a high wind watch compared to a WA, thus illustrating some difficulty navigating the watch/warning/ advisory hierarchy. With early results from the Hazard Simplification Project already reporting a "spectrum of comprehension" associated with the watch/ warning/advisory system (Eastern Research Group 2014), it is unclear whether our results are due to the common misconception of the word "advisory" or the discontinuity within the wind product language hierarchy (wind advisory versus high wind watch/ warning). Although NWS initiatives are attempting to redefine the watch/warning/advisory system and improve impact-based messaging, this study identifies the need to expand this research to include all hazards. Moreover, we hope this study contributes to further research examining the problematic areas of weather hazard communications and acts as a critical resource in approaching and solving the known issues associated with the current watch/warning/advisory system.

Acknowledgments. The authors thank Jared Rackley, Kelly Harris, Lynne Seymour, and Lauren Anderson for their comments during the development of the online survey. The authors also thank AthensGaWeather and Kevin Myatt at the Roanoke Times: Weather Journal for their help distributing and promoting the online survey. The authors acknowledge Dr. Andrew Grundstein and Dr. Alan Stewart for their comments on an earlier version of this manuscript. The authors thank Dr. James Correia Jr. and the two anonymous reviewers for their feedback, which greatly strengthened the manuscript. The first author (CAW) would like to acknowledge the support of the American Meteorological Society 21st Century Campaign Graduate Fellowship and a National Science Foundation Graduate Research Fellowship in the completion of this work (grant number DGE1443117). The third author (AWB) acknowledges support from NOAA Grant NA13OAR4310183. Any opinions, findings, conclusions, or recommendations expressed in this manuscript are those of the authors and do not necessarily reflect the views of the American Meteorological Society or the National Science Foundation.

\section{REFERENCES}

Agdas, D., G. D. Webster, and F. J. Masters, 2012: Wind speed perception and risk. PLoS ONE, 7, e49944, CrossRef.

Ashley, W. S., and A. W. Black, 2008: Fatalities associated with nonconvective high-wind events in the United States. J. Appl. Meteor. Climatol., 47, 717-725, CrossRef. 
Cronbach, L. J., 1951: Coefficient alpha and the internal structure of tests. Psychometrika, 16, 297-334, CrossRef.

Demuth, J. L., J. K. Lazo, and R. E. Morss, 2011: Exploring variations in people's sources, uses, and perceptions of weather forecasts. Wea. Climate Soc., 3, 177-192, CrossRef.

DeVellis, R. F., 1991: Scale Development: Theory and Applications. SAGE Publishing, 120 pp.

Eastern Research Group, Inc., 2014: The National Weather Service Hazard Simplification Project Social Science Research for Phrase I: Focus Groups [Available online at www.weather.gov/media/hazardsimplification/ Haz-Simp-Final\%20-Focus-Group\%20ReportPhase\%20I-TO\%20NOAA.pdf.]

Eastern Research Group, Inc., 2016: The National Weather Service's Hazard Simplification Project: Findings from the Case Studies [Available online at www.weather. gov/media/hazardsimplification/Final\%20Report $\% 20$ of $\% 20$ the $\% 20$ Case $\% 20$ Studies TO $\% 20$ NOAA 922 a16.pdf.]

Friday, E. W., 1994: The modernization and associated restructuring of the National Weather Service: An overview. Bull. Amer. Meteor. Soc., 75, 43-52, CrossRef.

Greenlaw, C., and S. Brown-Welty, 2009: A comparison of web-based and paper-based survey methods: Testing assumptions of survey mode and response cost. Evaluation Review, 33, 464-480, CrossRef.

Hayes, A. F., and K. Krippendorf, 2007: Answering the call for a standard reliability measure for coding data. Communication Methods and Measures, 1, 77-89, CrossRef.

Hsieh, H.-F., and S. E. Shannon, 2005: Three approaches to qualitative content analysis. Qualitative Health Research 15, 1277-1288, CrossRef.

Hugman, B., 2015: Perspectives on risk communication and gender issues, Medicines for Women. M. HarrisonWoolrych, Ed., Springer International Publishing, 531583, CrossRef.

Iowa Environmental Mesonet, cited 2015: Archived NWS Watch/Warnings. [Available online at mesonet.agron. iastate.edu/request/gis/watchwarn.phtml.]

Knox, J. A., J. D. Frye, J. D. Durkee, and C. M. Fuhrmann, 2011a: Non-convective high winds associated with extratropical cyclones. Geography Compass, 5, 63-89, CrossRef.

, and M. C. Lacke, 2011b: Death from a clear blue sky: Extreme non-convective high winds. Earthzine. [Available online at earthzine.org/2011/06/04/deathfrom-a-clear-blue-sky-extreme-non-convective-highwinds/.]

Krippendorff, K., 2004: Content Analysis: An Introduction to its Methodology (2nd ed.). SAGE Publishing, 456 pp.
Landers, R. N., 2011: "Where to place demographics on your surveys," NeoAcademic (blog), accessed 28 April 2016. [Available online at neoacademic.com/2011/12/07/ where-to-place-demographics-on-your-surveys/.]

Lacke, M. C., J. A. Knox, J. D. Frye, A. E. Stewart, J. D. Durkee, C. M. Fuhrmann, and S. M. Dillingham, 2007: A climatology of cold-season nonconvective wind events in the Great Lakes region. J. Climate, 20, 60126022, CrossRef.

Likert, R., 1932: A technique for the measurement of attitudes. Ph.D. dissertation, Columbia University, 55 pp. [Available online at legacy.voteview.com/pdf/ Likert 1932.pdf.]

Lindell, M. K., and R. W. Perry, 2012: The protective action decision model: Theoretical modifications and additional evidence. Risk Analysis, 32, 616-632, CrossRef.

Mortimer, M. J., and B. Kane, 2004: Hazard tree liability in the United States: Uncertain risks for owners and professionals. Urban Forestry and Urban Greening, 2, 159-165, CrossRef.

Mileti, D. S., and J. H. Sorensen, 1990: Communication of emergency public warnings: A social science perspective and state-of-the-art assessment. No. ORNL-6609, 162 pp. [Available online at www.osti.gov/scitech/servlets/ purl/6137387.]

Miller, P. W., A. W. Black, C. A. Williams, and J. A. Knox, 2016a: Maximum wind gusts associated with humanreported nonconvective wind events and a comparison to current warning issuance criteria. Wea. Forecasting, 31, 451-465, CrossRef.

2016b: Quantitative assessment of human wind speed overestimation. J. Appl. Meteor. Climatol. 55, 1009-1020, CrossRef.

NWS, 1992: WSOM Chapter C-44, Non-precipitation Weather Hazards. Operations Manual Issuance 926. [Available online at www.nws.noaa.gov/wsom/ manual/archives/NC449206.HTML\#d4-1.]

, cited 2015a: National Weather Service Glossary. [Available online at w1.weather.gov/glossary/].]

cited 2015b: WFO Non-precipitation Weather Products Specification. [Available online at www.nws. noaa.gov/directives/sym/pd01005015curr.pdf.] , cited 2015c: National Weather Service Wind Safety Tips and Resources. [Available online at www.nws.noaa. gov/om/wind/.] , cited 2015d: National Weather Service Impact Based Warnings. [Available online at www.weather.gov/ impacts/\#.Vfnx _hFViko.]

, cited 2015e: National Weather Service Hazards Simplification Project. [Available online at www.nws. noaa.gov/com/weatherreadynation/files/ HazSimp8.3.2015.pdf.] 
cited 2016: WFO Winter Weather Products Specification. [Available online at www.nws.noaa.gov/ directives/sym/pd01005013curr.pdf.]

Ripberger, J. T., C. L. Silva, H. C. Jenkins-Smith, and M. James, 2015: The influence of consequence-based messages on public responses to tornado warnings. Bull. Amer. Meteor. Soc., 96, 577-590, CrossRef.

Schmidlin, T. W., 2009: Human fatalities from wind-related tree failures in the United States, 1995-2007. Nat. Hazards, 50, 13-25, CrossRef.

Stewart, A. E., 2009: Minding the weather: The measurement of weather salience. Bull. Amer. Meteor. Soc., 90, 18331841, CrossRef.

, J. K. Lazo, R. E. Morss, and J. L. Demuth, 2012: The relationship of weather salience with the perceptions and uses of weather information in a nationwide sample of the United States. Wea. Climate Soc., 4, 172-189, CrossRef.

, C. A. Williams, M. D. Phan, A. L. Horst, E. D. Knox, and J. A. Knox, 2016: Through the eyes of the experts: Meteorologists' perceptions of the probability of precipitation. Wea. Forecasting, 31, 5-17, CrossRef.

Tavakol, M., and R. Dennick, 2011: Making sense of Cronbach's alpha. Int. J. Med. Edu., 2, 53-55, CrossRef.

Teclaw, R., M. Price, and K. Osatuke, 2012: Demographic question placement: Effect on item response rates and means of a veterans health administration survey. Journal of Business and Psychology, 27, 281-290, CrossRef.

UK Met Office, cited 2016: Met Office launches changes to the National Severe Weather Warning Service. [Available online at http://blog.metoffice.gov.uk/2011/03/.]

Wilks, D. S., 2006: Statistical Methods in the Atmospheric Sciences, 2nd ed. Academic Press, 627 pp. 